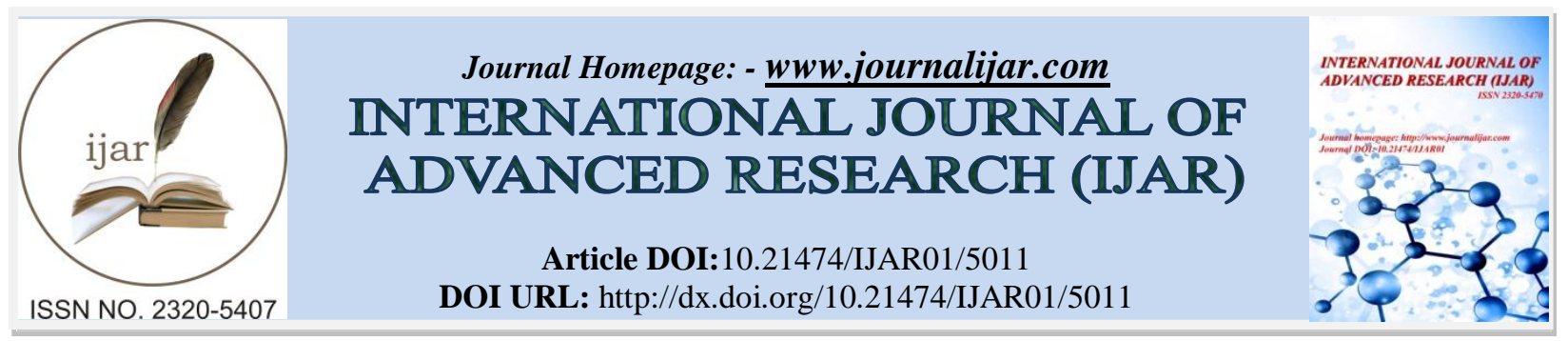

RESEARCH ARTICLE

\title{
FIXED TWIN BLOCK-HARNESSING THE REMAINING GROWTH: CASE REPORTS.
}

\section{Dr. Shweta Bhayade ${ }^{1}$, Dr. Kumar Niwlikar ${ }^{2}$, Dr. Vivek Shinde ${ }^{3}$, Dr. Snehalatha Narvekar ${ }^{4}$ and Dr. Minal Niswade 5 .}

1. Sr Lecturer, Department of Pedodontics and Preventive Dentistry, NRDCRC, Nanded.

2. Reader, Department of Orthodontics and Dentofacial Orthopaedics, NRDCRC, Nanded.

3. PG Student, Department of Orthodontics and Dentiofacial Orthopaedics, SDKSDCH, Nagpur.

4. Sr. Lecturer, Department of Oral and Maxillofacial Surgery, NRDCRC, Nanded.

5. PG Student, Department of Pedodontics and Preventive Dentistr, VSPMDC, Nagpur.

\section{Manuscript Info}

Manuscript History

Received: 28 May 2017

Final Accepted: 30 June 2017

Published: July 2017

\section{Abstract}

\section{Introduction:}

Skeletal class II division 1 is one of the most common type of malocclusion exhibiting retroganathic mandible as the most common feature. ${ }^{1}$ Treatment of class II division 1 depends upon the age of the patient, growth potential, severity of malocclusion and patient's compliance. Early treatment for class II malocclusion is frequently undertaken with the objective of correcting skeletal disproportion by altering the growth pattern.

Since its introduction by Dr. William Clark in 1977, "Twin Block Appliance" appliance has become one of the most widely used myofunctional appliance for the correction of class II as it is easy to fabricate, less bulky hence better patient acceptability, adaptability along with ease of incremental mandibular advancement without changing the appliance.

Twin Block appliances are simple bite blocks that are designed for full time wear which causes speedy functional correction of malocclusion by the transmission of favorable occlusal forces to occlusal inclined planes that cover the posterior teeth. The forces of occlusion are used as the functional mechanism to correct the malocclusion. ${ }^{2}$ However when compared with fixed functional appliances, the compliance of removable twin block appliance is not good particularly in cases which are near to maturation. ${ }^{3}$ The present case report aims to report two cases of skeletal class II malocclusion successfully treated using fixed twin block.

\section{Case report:}

A 13-year-old female patient reported to the Department of Pedodontics and Preventive Dentistry with a chief complaint of forwardly placed upper teeth. (fig 1) Clinical examination displayed a convex, retrognathic profile and incompetence lips at rest. The patient had a class II, division 1 malocclusion with an over-jet of $9 \mathrm{~mm}$ and an overbite of $5 \mathrm{~mm}$ and a pronounced Curve of Spee. (fig 2) clinically visual treatment objective (VTO) was positive. 
The lateral cephalogram confirmed a class II skeletal base relationship and the patient was in the cervical vertebral maturity index stage 4 . (table1 and fig 3).

A 2-stage treatment was planned in stage I, to reduce the skeletal discrepancy in antero-posterior plane, it was decided to treat the case with a fixed twin-block, followed by stage 2 consisting of fixed appliance for the final finishing and detailing of occlusion. Complete treatment plan was explained to parents and an informed consent was obtained. Impressions of maxillary and mandibular arches were made and bite registration was recorded for the fabrication of fixed twin block appliance. ${ }^{2}$ The appliance was constructed using clear acrylic followed by finishing and polishing. The upper and lower components of the fixed twin block were cemented with type I of glass inomer cement. All the necessary instructions regarding feeling of initial discomfort, pain, difficulty in speech and eating was imparted to the patients and their parents.

A 12 years old female patient reported to the Department of Pedodontics and Preventive Dentistry, with a chief complaint of mal-aligned teeth. A same treatment protocol as for case I was planned and followed for case II.

Case I

\begin{tabular}{|l|c|c|c|}
\hline & Normal & Pre Treatment & Post Functional Therapy \\
\hline SNA & $82^{\circ} \pm 2^{\circ}$ & $77^{0}$ & $82^{0}$ \\
\hline SNB & $82^{\circ} \pm 2^{\circ}$ & $75^{0}$ & $3^{0}$ \\
\hline ANB & $2^{\circ}$ & $2^{0}$ & $32^{0}$ \\
\hline Sn-GoGn & $32^{\circ}$ & $32^{0}$ & $22^{0}$ \\
\hline UI-NA & $22^{\circ}$ & $37^{0}$ & $4 \mathrm{~mm}$ \\
\hline UI-NA (LINEAR) & $4 \mathrm{~mm}$ & $12 \mathrm{~mm}$ & $58^{0}$ \\
\hline LI-NB & $25^{\circ}$ & $34^{0}$ & $110^{0}$ \\
\hline LI-NB (LINEAR) & $4 \mathrm{~mm}$ & $8 \mathrm{~mm}$ & $20^{0}$ \\
\hline Interincisal Angle & $131^{\circ}$ & $101^{0}$ & $50^{0}$ \\
\hline FMA & $25^{\circ}$ & $30^{0}$ & $110^{0}$ \\
\hline FMIA & $65^{\circ}$ & $45^{0}$ & $2 \mathrm{~mm}$ \\
\hline IMPA & $90^{\circ}$ & $105^{0}$ & $3 \mathrm{~mm}$ \\
\hline E Line-Upper Lip & - & $1 \mathrm{~mm}$ & - \\
\hline E Line- Lower Lip & - & $1 \mathrm{~mm}$ & - \\
\hline Nasolabial Angle & $102^{\circ} \pm 8^{\circ}$ & - & - \\
\hline Overjet & $2 \mathrm{~mm}$ & $9 \mathrm{~mm}$ & \\
\hline Overbite & $2 \mathrm{~mm}$ & $5 \mathrm{~mm}$ & \\
\hline
\end{tabular}

Case II

\begin{tabular}{|l|c|c|c|}
\hline & Normal & Pre Treatment & Post Functional Therapy \\
\hline SNA & $82^{\circ} \pm 2^{\circ}$ & $80^{0}$ & $82^{0}$ \\
\hline SNB & $82^{\circ} \pm 2^{\circ}$ & $78^{0}$ & $3^{0}$ \\
\hline ANB & $2^{\circ}$ & $4^{0}$ & $27^{0}$ \\
\hline Sn-GoGn & $32^{\circ}$ & $30^{0}$ & $22^{0}$ \\
\hline UI-NA & $22^{\circ}$ & $28^{0}$ & $42 \mathrm{~mm}$ \\
\hline UI-NA (LINEAR) & $4 \mathrm{~mm}$ & $8 \mathrm{~mm}$ & $92^{0}$ \\
\hline LI-NB & $25^{\circ}$ & $54^{0}$ & $116^{0}$ \\
\hline LI-NB (LINEAR) & $4 \mathrm{~mm}$ & $6 \mathrm{~mm}$ & $29^{0}$ \\
\hline Interincisal Angle & $131^{\circ}$ & $78^{0}$ & $40^{0}$ \\
\hline FMA & $25^{\circ}$ & $23^{0}$ & $110^{0}$ \\
\hline FMIA & $65^{\circ}$ & $54^{0}$ & $0 \mathrm{~mm}$ \\
\hline IMPA & $90^{\circ}$ & $101^{0}$ & $3 \mathrm{~mm}$ \\
\hline E Line-Upper Lip & - & $1 \mathrm{~mm}$ & - \\
\hline E Line- Lower Lip & - & $5 \mathrm{~mm}$ & $4 \mathrm{~mm}$ \\
\hline Nasolabial Angle & $102^{\circ} \pm 8^{\circ}$ & - & $3 \mathrm{~mm}$ \\
\hline Overjet & $2 \mathrm{~mm}$ & $7 \mathrm{~mm}$ & \\
\hline Overbite & $2 \mathrm{~mm}$ & $5 \mathrm{~mm}$ & \\
\hline
\end{tabular}




\section{Case I:}
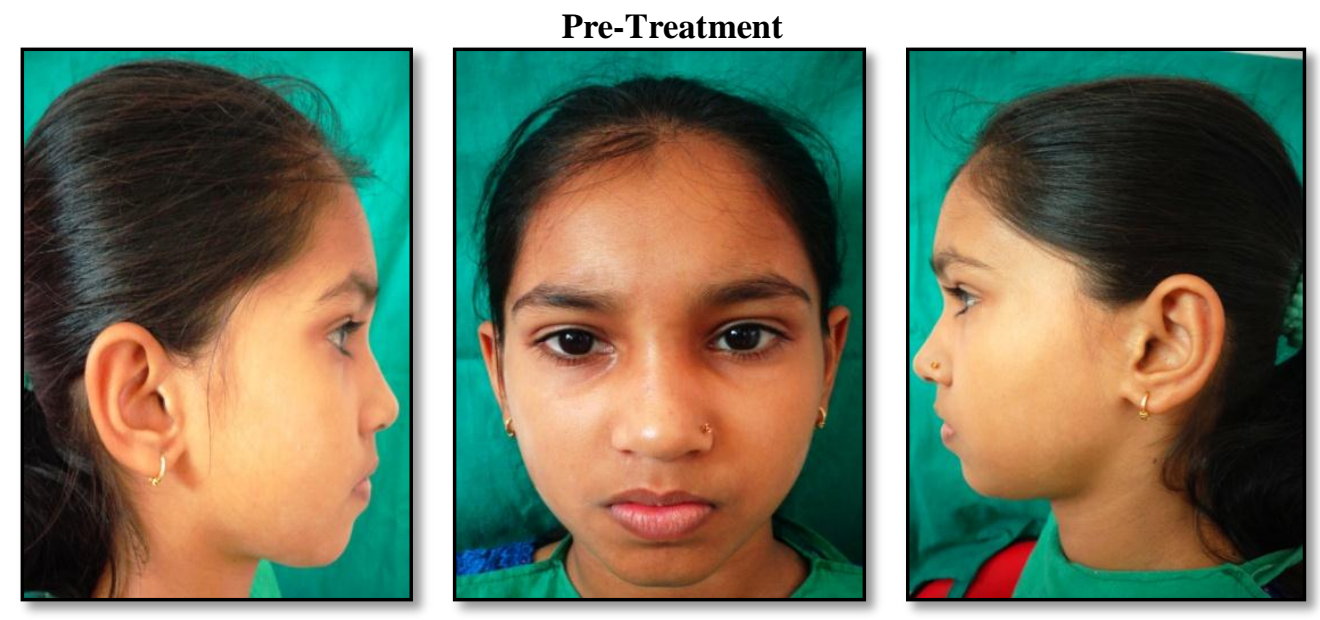

Pre Treatment extra-oral photographs
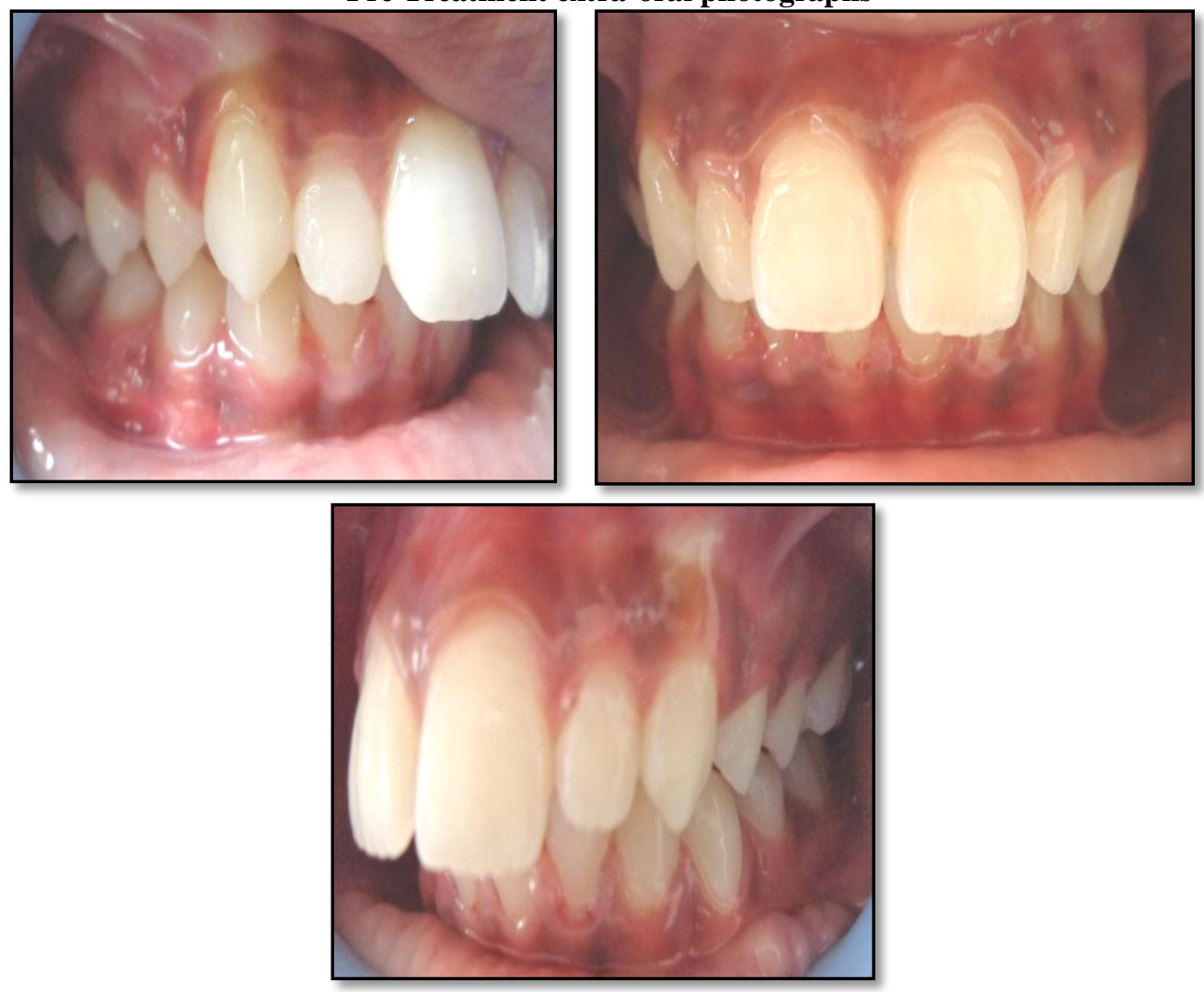

Pre Treatment intra-oral photographs 

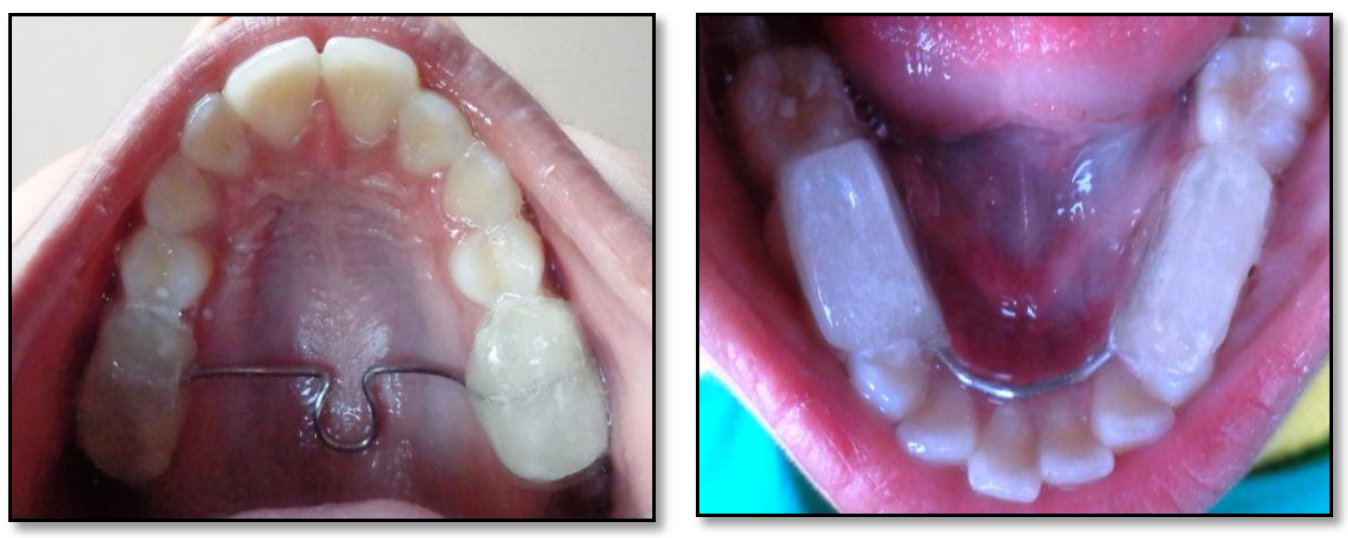

Intra-oral photographs demonstrating fixed twin block
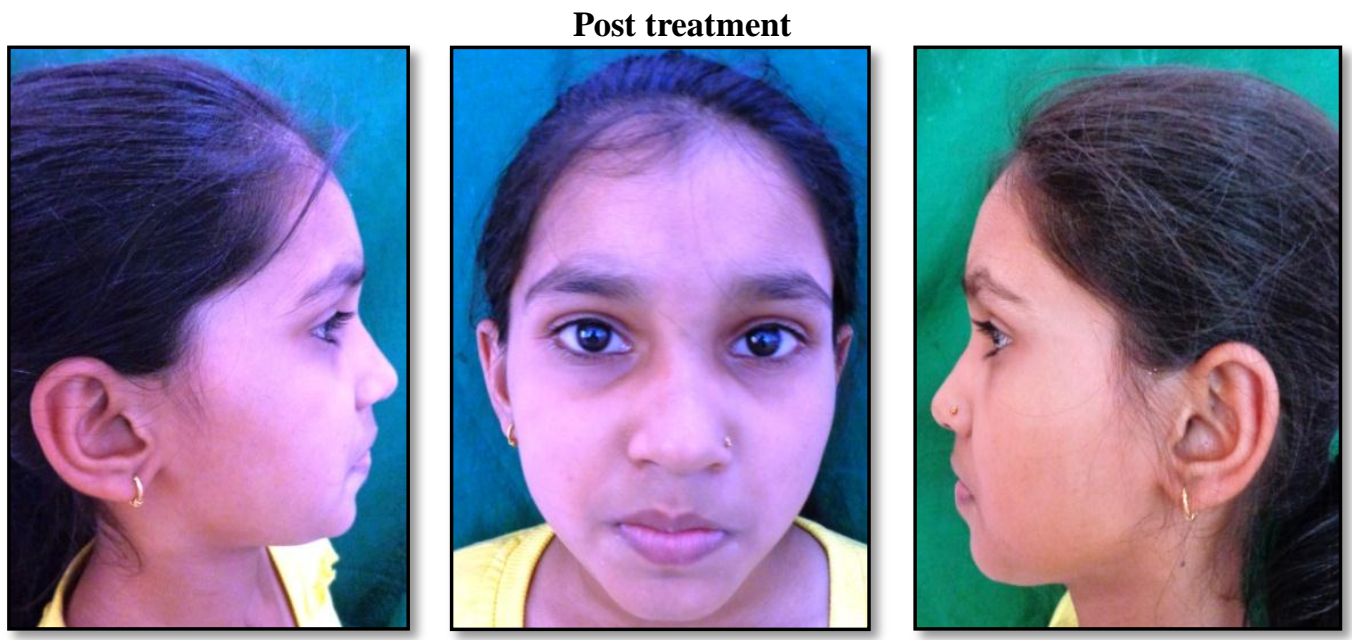

Post Treatment extra-oral photographs 

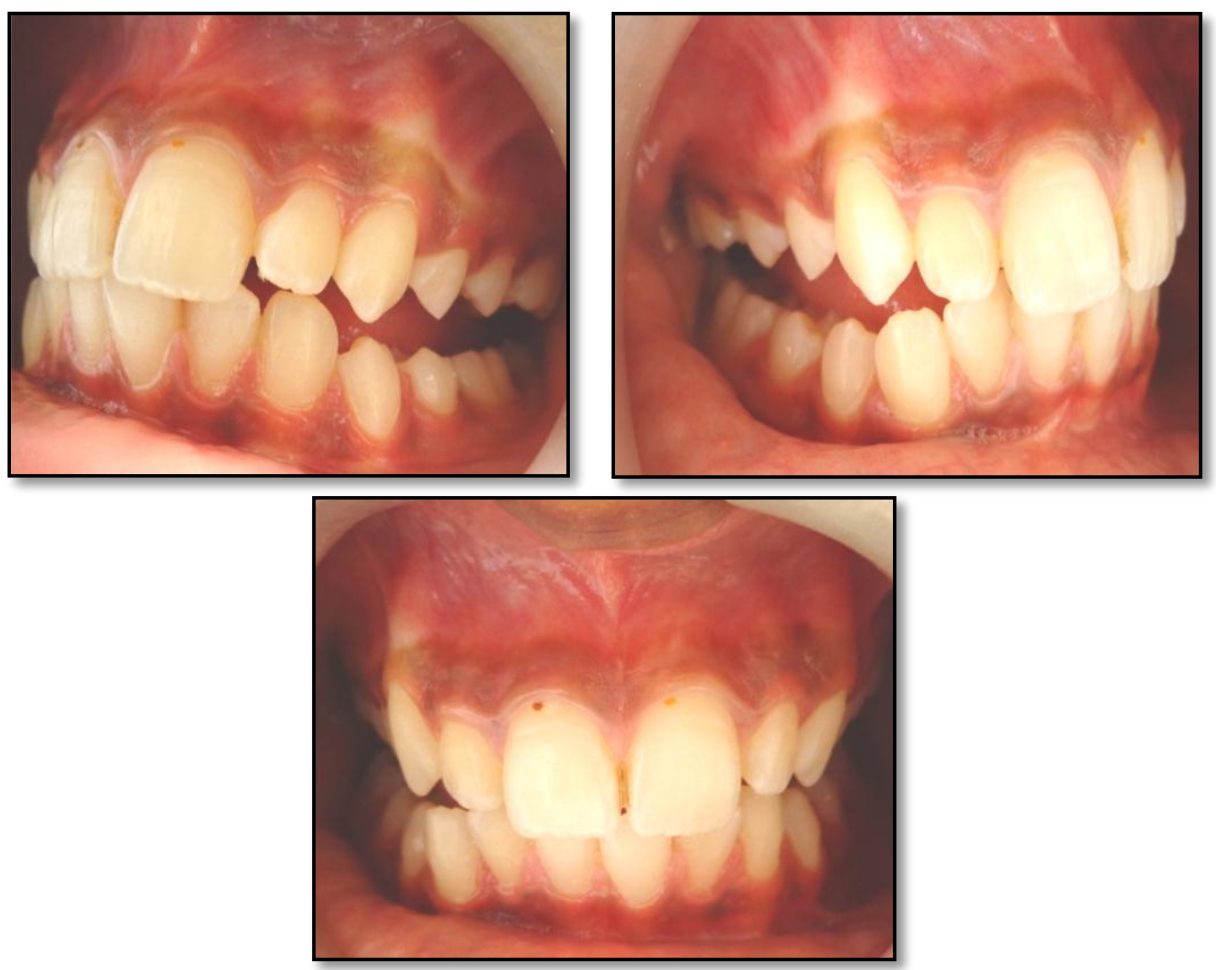

Post Treatment intra-oral photographs

\section{Case II:}
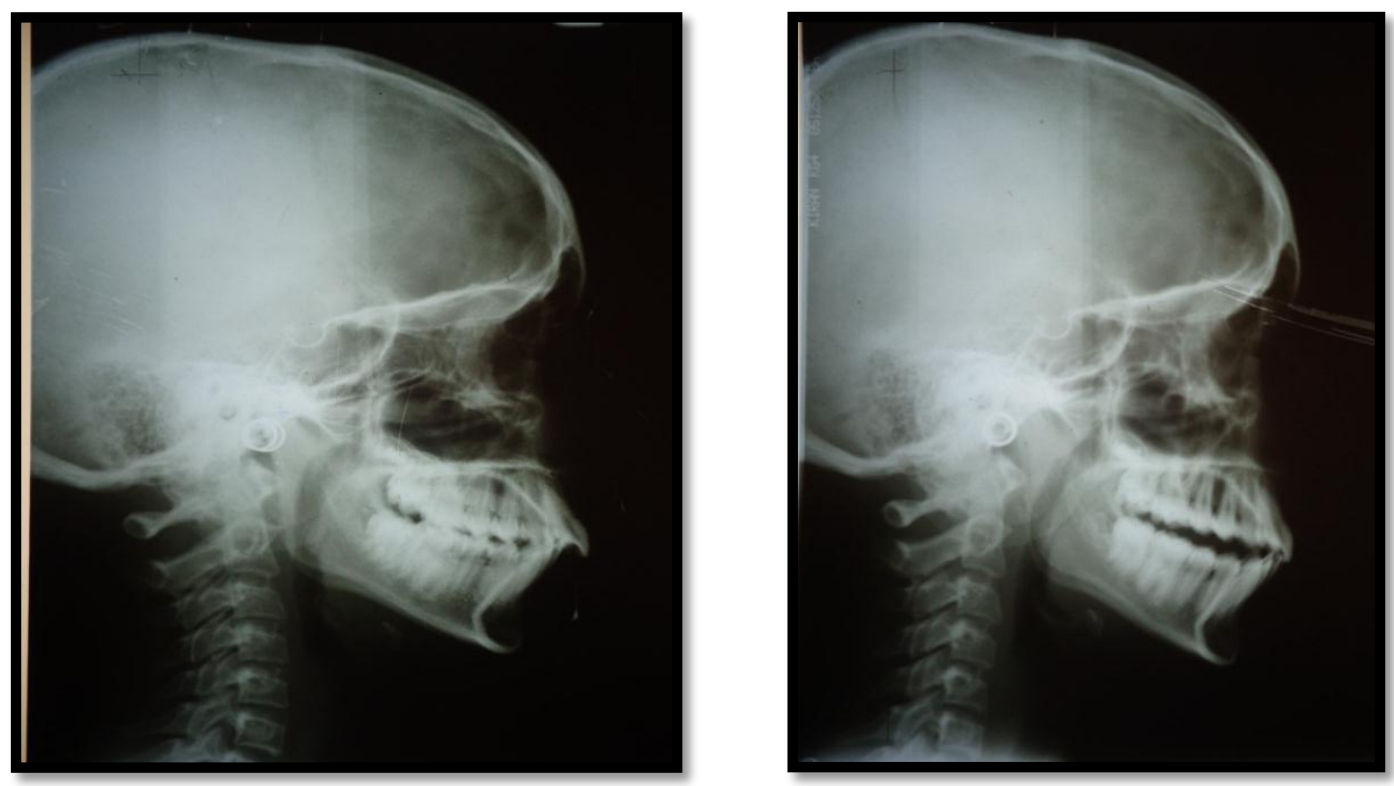

Pre Treatment post treatment 
Pre Treatment analysis

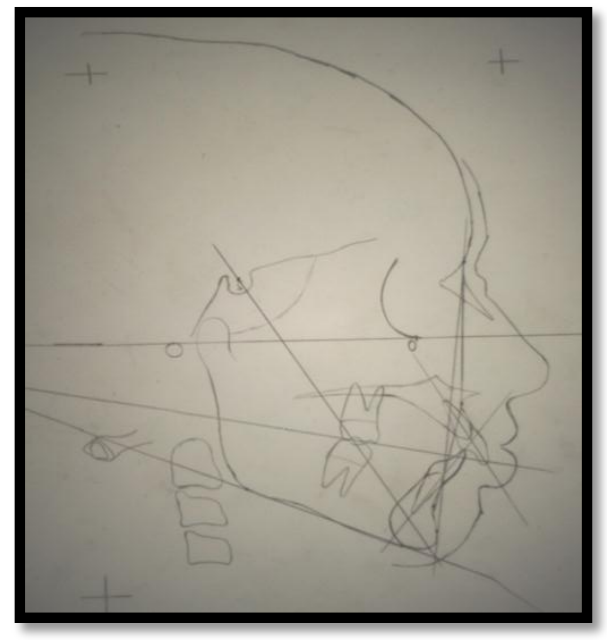

Downs analysis

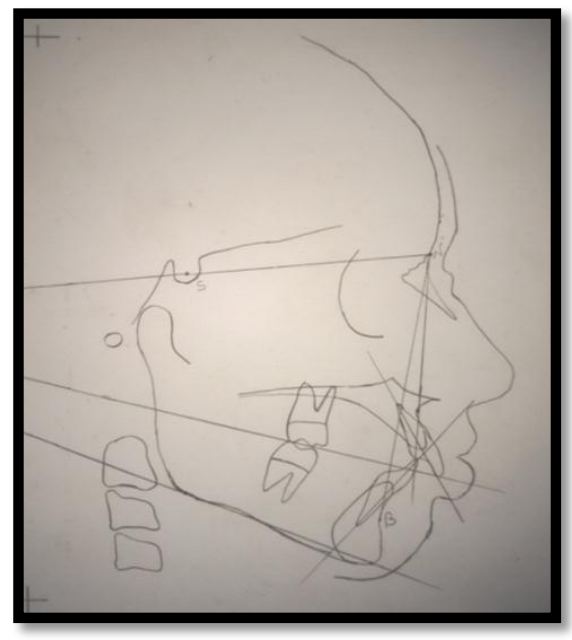

steiner's analysis

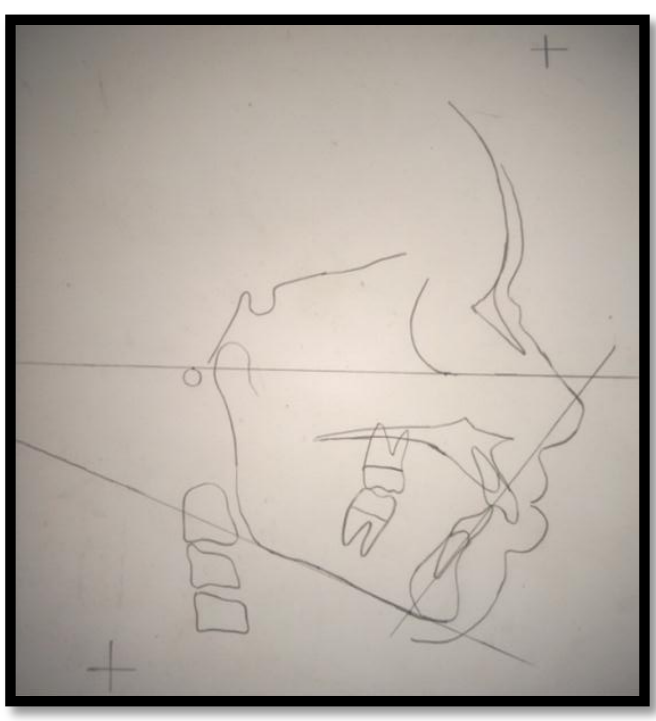

Tweeds analysis 


\section{Post Treatment analysis}

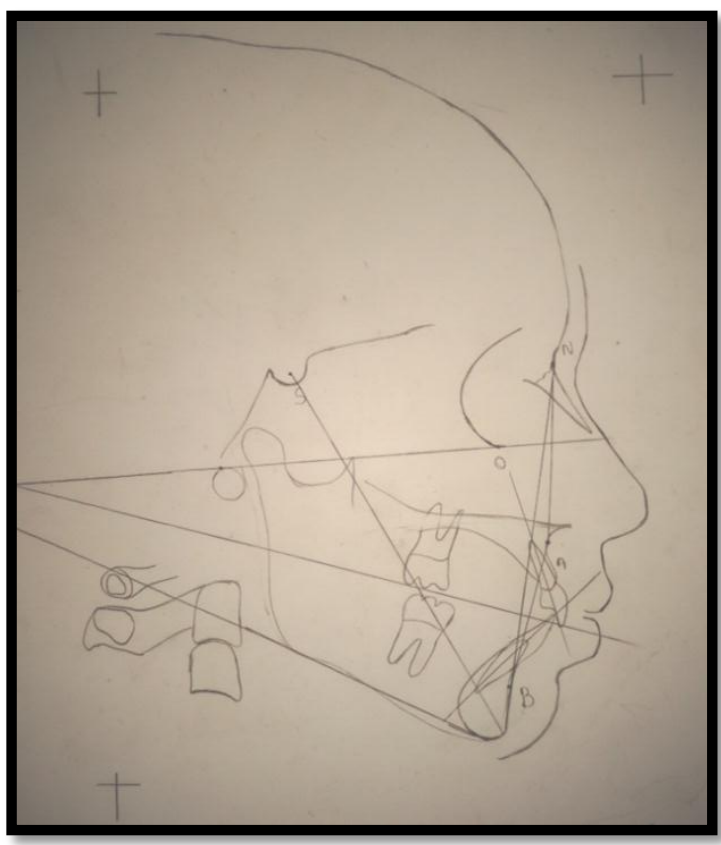

Downs analysis

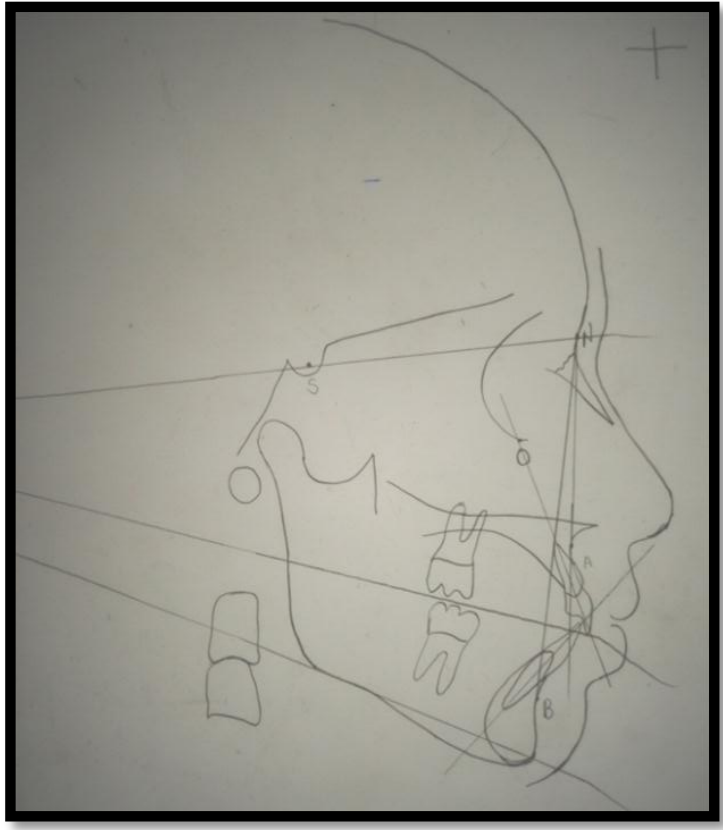

Steiner's analysis

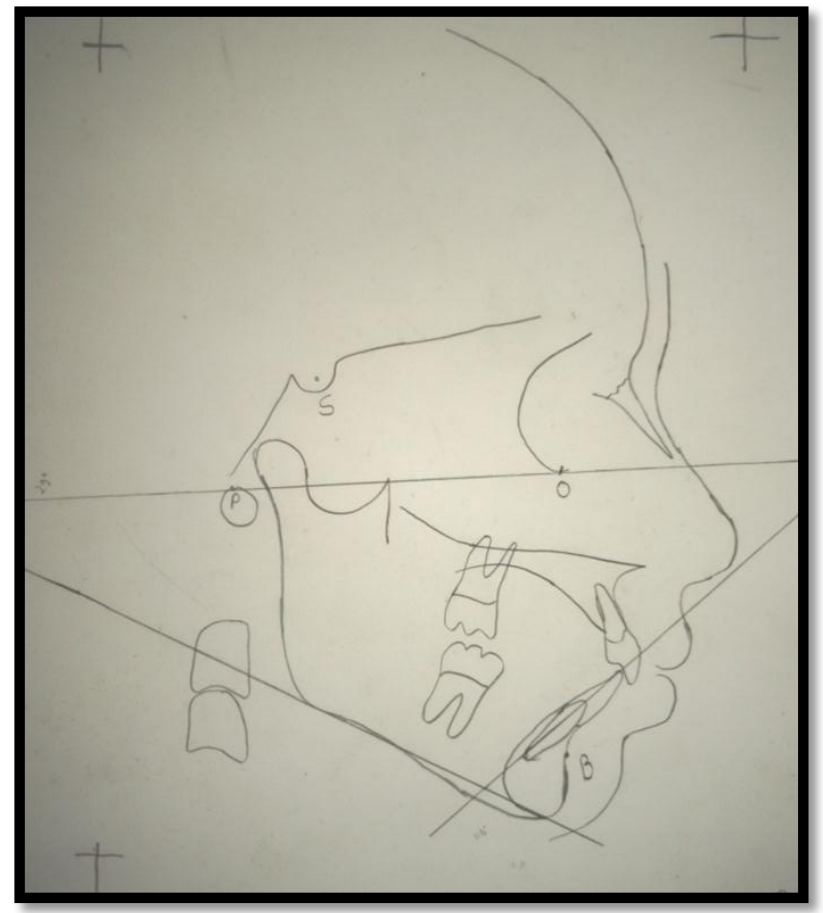

Tweeds analysis

\section{Discussion:-}

The best way to intercept the developing malocclusion in mixed dentition is by using myo-functional appliance as their main goal is to bring about the changes in the skeletal bases by striating the muscles which eventually redirects the growth pattern of jaws bases and achievement of desirable occlusion.

Amongst the myo-functional appliances, removable twin block appliance is widely used because of its ease of fabrication and better patient compliance. A variant of removable twin block, the fixed type had been used mainly in 
the late mixed dentition/early permanent dentition to harness the remaining growth and to obtain proper relationship between maxillary and mandibular jaw bases and establish class i molar relationship.

\section{References:-}

1. Mcnamara J. Component of class ii malocclusion in children 8-10 years of age. Angle Orthod 1981;51:177-202.

2. Clark WJ. Twin-block functional therapy. Ed 1. Mosby Wolfe, London; 1995.

3. Kevin O Brien, Jean Wright, Frances Conboy, Yewengsanjie, Nicky mandall. Effectiveness of early orthodontic treatment with the twin block appliance: a multicenter randomized controlled trial: skeletal and dental effects. Am J Orthoddentofacorthop 2003; 124(3): 234-243. 